\title{
Programas de rastreamento do câncer de mama através de mamografias: primeira aproximação
}

\author{
Erney Plessmann de Camargo \\ Mônica Teixeira
}

Nos últimos trinta anos, o segmento da força de trabalho que mais cresceu nos Estados Unidos foi o dos tecnólogos da medicina. A observação apareceu na reportagem principal da edição de 5 de novembro de 2001 da revista inglesa The Economist, em texto assinado por Peter Drucker sobre a "sociedade do conhecimento" - um dos nomes que usamos quando queremos descrever o futuro... contemporâneo: tal como o sonhamos no presente. A proliferação destes postos de trabalho evidencia a potência da crença talvez a mais disseminada no mundo ocidental: aquela que erige a medicina em glória da racionalidade humana, triunfo da espécie, da qual a expressiva dilatação da nossa expectativa de vida, atribuída a seus avanços, é freqüentemente chamada a testemunhar. Como se apresenta a medicina à qual atribuímos este triunfo? Como aquela aliada a uma certa técnica (certa porque depurada de todo interesse) para curar corpos dos quais subtrai o que escapa a esgotar-se em biologia; ao fazê-lo, para fazê-lo, esta medicina arrisca-se a tornar seus praticantes presas cegas desta aliança e de seus pressupostos. A invenção de aparelhos atendendo o desejo de olhos querendo ver dentro deste corpo esgotável (e vivo) fez brotar imagens que, 
interpretadas, permitem aos médicos sustentar saber antes. Saber antes, informa o pressuposto enraizado neste território do senso comum, revigora a potência desta medicina triunfante, e homenageia tanto a eficácia indisputada da prevenção quanto seu caráter inofensivo para quem "se previne”. A revisão Systematic Review of Screening for Breast Cancer with Mammography, escrita e preparada por Ole Olsen e Peter Gotzsche (2001), respectivamente diretor de pesquisa e diretor do Nordic Cochrane Centre, sediado em Copenhagen, Dinamarca, desafia este edifício de crenças. Encomendada em 1999 aos autores, pelo instituto dinamarquês de avaliação das tecnologias médicas, a revisão levou Gotzsche e Olsen a afirmar que os resultados apresentados pelos programas de rastreamento de câncer de mama postos em prática por países como a Inglaterra e a Suécia não permitem afirmar que a mortalidade das mulheres incluídas nos programas, por câncer de mama, ou por qualquer outra causa, tenha diminuído; e, achado mais controverso, que estas mulheres sofrem mais mastectomias, tumorectomias e mais radioterapia do que as não rastreadas, podendo resultar em piora de seus índices de mortalidade.

O caso não começou no último dia 20 de outubro, quando a revisão foi publicada tal como escrita por seus autores no site da Lancet, e modificada (pelos editores) na Cochrane Library (Olsen \& Gotzsche, 2001a), mas teve em Screening Mammography - an overview revisited (Horton, 2001: 1284) comentário assinado pelo editor-chefe, Richard Horton, uma reviravolta importante. O comentário lembra que os dois autores já haviam afirmado a falta de justificativas para programas de screening por mamografia em janeiro de 2000, na própria Lancet, como conclusão da revisão agora apresentada de forma mais completa e ampliada; e apóia enfaticamente o resultado: "No momento", diz Horton ao encerrar seu texto, "não há evidência confiável de grandes ensaios clínicos para apoiar programas de rastreamento por mamografia”.

\section{Supressão; inserção}

Para preparar a revisão, os autores debruçaram-se sobre sete ensaios clínicos, realizados a partir dos anos, 1960, dois deles ainda em curso, envolvendo meio milhão de mulheres, como contam na Research Letter (Olsen \& Gotzsche, 2001b: 1340) publicada na edição da Lancet de 20 de outubro. Gotzsche e Olsen compararam fatores diversos - mortalidade por câncer de mama, mortalidade por qualquer causa, uso de intervenções cirúrgicas, uso de terapia coadjuvante, mortalidade por outros cânceres, efeitos adversos causados pela mamografia, como resultados falsopositivos, por exemplo - entre mulheres participantes e não participantes de programas de rastreamento. A Cochrane Collaboration é uma rede internacional de pesquisadores dedicada exatamente a isto: aplicar tratamento estatístico (meta-análise) a dados extraídos dos ensaios clínicos aleatórios disponíveis em determinado tópico. A meta-análise, pressupõe a Cochrane Collaboration, permite deduzir, da somatória 
dos dados, novos resultados, consolidados e confiáveis, orientando a prática de uma medicina que quer se basear em evidências (Camargo e Teixeira, 2001). Olsen e Gotzsche, ativos colaboradores da rede, usaram metodologia submetida a avaliação da própria Cochrane Collaboration para realizar a revisão, e por ela aprovada em 2000. Antes de tudo, os autores concluíram que os ensaios clínicos disponíveis não são de boa qualidade e nem sempre podem ter os resultados comparados. Segundo sua avaliação, os dois melhores ensaios clínicos foram classificados como de qualidade média, e justamente estes dois não mostram efeito do programa de rastreamento sobre a mortalidade atribuída a qualquer câncer, incluído aí o câncer de mama. Os autores descrevem cuidadosamente o trabalho feito e o método de avaliação da qualidade dos dados na revisão, tanto na versão disponível no site da Lancet, quanto naquela publicada na Cochrane Library.

Mas os editores do grupo Cochrane para Câncer de Mama não admitiram as conclusões de Olsen e Gotzsche e, por isso, suprimiram afirmações do texto dos autores, e inseriram outras, tornando as duas versões diferentes. Supressão e inserção ocorreram nas seções chamadas "Resultados Principais” e "Conclusões dos Revisores”, ambas integrantes do resumo do artigo. Faltou os autores dizerem, no texto editado pela Cochrane, que “... o número de mastectomias e tumorectomias e o número de mulheres que receberam radioterapia foram significativamente mais altos nos grupos rastreados (Olsen \& Gotzsche, 2001). Também ficou faltando, nas “Conclusões”, os autores terem o direito de dizer (suprimiu-se o que está em itálico): “A evidência confiável atualmente disponível não mostra um benefício na sobrevivência advindo do rastreamento em escala para câncer de mama (e a evidência é inconclusiva para a mortalidade por câncer de mama), embora tenha sido mostrado que o rastreamento em escala aumenta o tratamento agressivo (Ibid.). Por outro lado, os editores inseriram nos "Resultados Principais", duas vezes, afirmações sobre dados retirados dos ensaios clínicos descartados pelos autores por serem inconsistentes. Como aqui: "Os melhores ensaios falharam em mostrar uma redução significativa na mortalidade por câncer de mama com um risco relativo de 0.97 (95\% CI 0.82-1.14). Se dados de todos os ensaios elegíveis (excluindo aqueles inconsistentes) são considerados, então o risco relativo para câncer de mama depois de 13 anos é de 0,80 (95\% CI 0.71-0.89)" (Olsen \& Gotzsche, 2001a).

A decisão Cochrane de suprimir e inserir estes trechos desagradou francamente The Lancet. Nas palavras de Richard Horton, “... a interferência dos editores ao inserir o que os autores da revisão acreditam ser análise não válida erode a liberdade acadêmica destes investigadores. Editores fazem recomendações para autores todo o tempo, mas editores insistindo em análises inapropriadas, parecendo dar suporte a um particular ponto de vista, ferem não somente a eles próprios e à instituição que representam, mas também a credibilidade da ciência que eles dizem valorizar” (Horton, 2001: 1284). A ação destes editores parece ter movido a Lancet a apoiar 
publicamente as posições de Olsen e Gotzsche sobre os programas de rastreamento por mamografia, o que não havia acontecido durante a tempestade de debate e crítica que, nas palavras de Horton, havia se desencadeado sobre os autores quando da publicação do artigo de janeiro de 2000, Is screening for breast cancer with mammography justifiable? (Gotzsche \& Olsen, 2000: 129-34), dando início ao caso.

\section{Eficácia dos programas de screening}

O comentário de Harry de Koning (2000: 80-81) com que a Lancet fez acompanhar o artigo sobre mamografia e rastreamento de câncer publicado em 2000, mostra que o debate sobre a eficácia e os aspectos éticos dos programas de rastreamento não é novo. Escreve o docente da Universidade de Roterdã, e membro da equipe de avaliação do programa de screening holandês: "Rastreamento de câncer tem sido sempre altamente controverso, em parte porque o procedimento é para pessoas aparentemente saudáveis, para as quais o benefício tem que ser muito claro. (...) A nível individual, a predição sobre quem vai se beneficiar e quem vai sofrer mais mal do que bem é impossível. O equilíbrio entre efeitos favoráveis e desfavoráveis é delicado". No caso do câncer de pulmão, por exemplo, os programas de rastreamento usando teste de escarro e raio $\mathrm{X}$ do peito foram descartados porque falhavam, justamente, em mostrar impacto sobre a mortalidade causada pela doença. Em 30 de novembro de 2000, o New England Journal of Medicine publicou a revisão Screening for Lung Cancer (Patz, Goodman, Bepler, 2000: 1627-33). Escrevem os autores: "Apesar de a sobrevida a partir do momento do diagnóstico da doença ser comumente registrada em ensaios de rastreamento, ela não é uma medida apropriada e pode ser enganadora porque está sujeita a vícios de curto e longo prazos e vícios de superdiagnóstico". Estas distorções influem nos resultados e ajudam a entender porque é difícil demonstrar o impacto dos programas de rastreamento sobre a mortalidade causada pela doença rastreada, contrariando o que nos informa, com força, o senso comum a respeito da correlação entre detecção precoce e cura.

Primeiro, o vício de curto prazo (lead-time bias). No grupo rastreado, imaginemos ter acontecido o diagnóstico antes do aparecimento de um sintoma. Do momento diagnóstico até o paciente morrer, esta será a sobrevida para aquele paciente. No grupo controle, o diagnóstico deverá acontecer mais tarde - depois do aparecimento do sintoma. A sobrevida será provavelmente menor, porque o diagnóstico foi feito mais tarde; mas nada garante (inclusive porque é impossível comparar) que o paciente no grupo rastreado viverá mais ou menos do que o paciente do grupo de controle. O vício de longo prazo (length-time bias) é um pouco diferente, e diz respeito à velocidade de crescimento dos tumores. Tumores muito agressivos, crescendo rápido, mais provavelmente serão detectados por se tornarem sintomáticos, e sua incidência será praticamente idêntica para o grupo sob 
rastreamento e o grupo controle, exercendo impacto semelhante sobre os resultados da sobrevida. Contudo, os tumores de crescimento mais demorado serão os "pegos" preferencialmente no grupo sob rastreamento; e o cômputo destes tempos aparentemente maiores de sobrevida incidirão a favor do grupo rastreado em relação ao grupo controle. Finalmente, o efeito do superdiagnóstico: os tumores que não seriam detectados se não fosse o programa de rastreamento, e que não teriam efeito sobre o tempo de vida do paciente - porque ele morreria de outras causas, por exemplo - criam o efeito aparente de alongar a vida do grupo sob rastreamento em relação ao grupo controle, em que estes tumores simplesmente não foram detectados, e da mesma forma não afetaram a duração de vida do paciente.

Razões como estas, e outras clínicas, influem na presumida eficácia da detecção precoce dos tumores que os programas de rastreamento, supõe-se, proporcionam. No caso dos programas de rastreamento de câncer de pulmão postos em prática na década de 1950 (e os únicos disponíveis para análise), apesar da incidência aumentada de tumores mais precoces, de mais tumores extirpáveis terem sido encontrados, e de se encontrar taxas melhores de sobrevida de cinco anos entre o grupo rastreado do que no grupo controle, ainda assim, não houve diferença estatística significativa na mortalidade atribuída ao câncer de pulmão entre os dois grupos (Ibid.). Os autores do estudo não recomendaram, ao final, a adoção de programas de rastreamento de câncer de pulmão por tomografia computadorizada.

\section{Discrepâncias}

Seguiu-se à publicação da revisão de Olsen e Gotzsche, em outubro, um pronunciamento do National Health Service britânico reafirmando os benefícios do programa de rastreamento em escala do câncer de mama praticado desde 1985 no Reino Unido. Segundo o NHS, a mortalidade por câncer de mama entre mulheres de 55 a 69 anos caiu 21,3\%. Desta queda, afirma texto (Moscrop, 2001) publicado no British Medical Journal, 6,4\% são atribuídas ao programa de rastreamento. Por outro lado, na revisão publicada pela Cochrane Library, os editores, na seção chamada “Comentários e Críticas”, informam que só serão publicados os dados referentes às conseqüências sobre o tratamento dos programas de screening depois de uma mais profunda avaliação editorial. Sobre os resultados envolvendo mortalidade e morbidade dos programas, os editores informam: foi a diligência dos autores, e o fato de eles terem procedido de acordo com o protocolo da Cochrane Collaboration, que os fez decidir pela publicação dos dados e das conclusões, apesar de não haver unanimidade a respeito disto. Um dos membros do grupo Cochrane, para câncer de mama, professor Alessandro Liberati, declarou ao BMJ: o problema é uma questão de interpretação de um mesmo conjunto de dados (Mayor, 2001). Isto mostra, segundo o professor e o texto da reportagem, que mesmo entre cientistas, "tentando com 
afinco ser rigorosos e metodologicamente corretos”, a subjetividade intervém. Esta intervenção da subjetividade, este conflito de interpretações, são argumentos chamados a desqualificar e diminuir a importância dos achados de Olsen e Gotzsche.

\section{Um clínico, uma paciente}

Um jovem oncologista, clínico, especialista em câncer de pulmão, sabedor das limitações dos programas de rastreamento, de sua discutível eficácia para a mortalidade específica e geral, pergunta: mas, fora destes exames periódicos, o que um médico poderá oferecer ao paciente na prevenção de tumores? Na edição de 29 de janeiro de 2001 da revista New Yorker ele poderá talvez encontrar uma resposta no artigo "Betting your Life” (Trillin, 2001), publicado sob a rubrica Personal History. Em texto muito sincero e vívido, Alice Stewart Trillin narra seu itinerário quando uma intensa e persistente dor nas costas, em seguida a um forte resfriado, examinada por meio de exames de ressonância magnética e raios X, foi interpretada como indicativa de doença metastática - já que Alice, 14 anos antes, havia tido um câncer retirado do pulmão. No Memorial Sloan Kettering Cancer Center, ela passou por exames de raio $\mathrm{X}$, duas biópsias do fluido do pulmão, uma ressonância magnética de todo o corpo, duas biópsias de osso, dois exames de rastreamento de câncer no esqueleto, em busca de um sinal inequívoco da doença. Nada. De resultado chamado de "inconclusivo" - uma vez que não confirmava a suspeita da esperada metástase - em resultado "inconclusivo", Alice passou por quatro médicos. Um deles, cirurgião, sugeriu retirar uma das vértebras de sua coluna, que aparecia iluminada na imagem produzida pela ressonância magnética (a luz sendo interpretada como tumor) e substituí-la por uma de aço, para que pudesse se assenhorear da vértebra retirada e assim adquirir a certeza sobre haver ou não, ali, uma metástase do câncer primeiro no pulmão. Ela descreve assim a expectativa que a impulsionava: queria repetir o que fizera quando teve o câncer do pulmão diagnosticado. "A coisa importante (...) era se mover com rapidez (...). Sempre foi este o conselho que eu dava a quem me procurava quando descobria que tinha câncer. Decisões médicas sérias não são decisões filosóficas, raios X, e escaneamentos, e biópsias são a chave; a ciência vai lhe dizer o que fazer" (Trillin, 2001: 40).

Alice precisou chegar a um quinto médico - o chefe do serviço de oncologia de tórax do hospital, Mark Kris - para ser examinada, pela primeira vez no itinerário, ela própria, seu corpo, não as imagens fornecidas pela tecnologia médica. "Foi o primeiro exame físico desde que o drama começara”, registra a narração. "Quando acabou, ele me perguntou como eu me sentia. Foi a única vez em meses que alguém me fez esta pergunta”. Um tanto estupefata, Alice conta que Kris afirmou não saber se o visto nos exames era ou não a metástase de ossos que o anterior câncer do pulmão fazia os médicos preverem, e aconselhou-a, simplesmente, a esperar. "Eu 
não podia acreditar no que estava ouvindo, ou no que eu estava sentindo”, conta ela. "Um sabidíssimo doutor estava me pedindo para eu viver com a possibilidade de ter cinco tumores crescendo em meus ossos, e não fazer nada a não ser esperar e observar. $\mathrm{O}$ conselho ia contra tudo aquilo em que eu acreditava sobre agir agressivamente para lutar contra o câncer.”

Alice, então, pôde confiar no médico que, na descrição dela, “... foi capaz de ver os cálculos matemáticos de meu caso num contexto mais abrangente que os cirurgiões e radiologistas”. Ela pôde simplesmente esperar. O que aparecia como imagens de um tumor nas representações da tecnologia médica podia ser interpretado também como cicatrizes da radioterapia. Quando o artigo foi publicado na New Yorker, já haviam se passado quase dez anos. E se fosse câncer? perguntou então a já mais paciente Alice a Mark Kris, durante a inesquecível consulta. Ao responder a ela, o oncologista americano também responde, obliquamente, à questão do oncologista brasileiro. Ele disse: "Se for câncer, você voltará aqui e eu lhe direi o que poderemos fazer".

\section{Referências}

Camargo, E.P.; TeixeIRA, M. Medicina baseada em evidência: avanços e problemas. Revista Latinoamericana de Psicopatologia Fundamental. São Paulo: Escuta, vol. IV, nº 3, setembro de 2001.

DE Koning, H.J. Assessment of nationwide cancer-screening programmes. Lancet 2000; 355: 80-81.

Gotzsche, P.C.; Olsen, O. Is screening for breast cancer with mammography justifiable? Lancet 2000; 355: 129-34.

HoRTON, R. Screening mammography - an overview revisited. Lancet 2001; 358: 1284.

MAYOR, S. Row over breast câncer screening shows that scientists bring "some subjectivity into their work”, BMJ 2001: 323, 27 de outubro.

Moscrop, A. NHS breast cancer screening report contradicts Cochrane findings. BMJ 2001; 323, 10 de novembro.

Olsen, O. \& Gotzsche, P.C. Systematic Review of Screening for Breast Cancer with Mammography, www.the1ancet.com, 20.10.2001.

Screening for breast cancer with mammography (Cochrane Review). The Cochrane Library, 4, 2001a. Oxford: Update Software.

Cochrane Review on screening for breast cancer with mammography. Lancet 2001b; 358: 1340.

Patz, E.F.; Goodman, P.C.; Bepler G. Screening for Lung Cancer. NEJM, 2000; 343: 162733.

TriLlin, A.S. Betting your life. The New Yorker, 29 de janeiro de 2001. 